\title{
Comparison of Two Different Methods in Reducing Pain and Fear due to Dressing Change in 7-10 Years Old Children
}

\author{
(1) Fatma Özsoy', (1) Bahire Ulus² \\ 'University of Health Sciences Turkey, İstanbul Bağcılar Training and Research Hospital, İstanbul, Turkey \\ ${ }^{2}$ Retired Faculty Member, Maltepe İstanbul, Turkey
}

\begin{abstract}
Aim: This randomized controlled study aims to analyze the effects virtual reality (VR) and carton distraction techniques pain due to dressing change and fair levels in children that underwent abdominal surgery.

Materials and Methods: The study was conducted on 96 children between 7 and 10 years of age, who visited pediatric surgery department of University of Health Sciences Turkey, İstanbul Bağcılar Training and Research Hospital between 1 November 2018 and 30 November 2019. Personal information form on children and parents, Wong-Baker faces pain rating scale and children's fear scale were used for data collection. Due to dressing change, no intervention was made to the children in the first group whereas children in the second and third groups watched video with VR headset and cartoon from tablet, respectively. Pain severity and fear levels were self-assessed. Descriptive statistics, correlation analysis, Wilcoxon signed-rank, Kruskal-Wallis, Mann-Whitney U, Pearson's chi-square and Fisher-Freeman-Halton exact tests were used for data analysis. Statistical significance was set at $p<0.05$.

Results: Mean age of children was $8.58 \pm 1.13$ and $56.3 \%(n=54)$ were male. Pain and fear scores due to dressing change were lower for the VR and carton distraction groups. Statistically significant difference between the control and the distraction groups stemmed from the VR distraction group ( $\mathrm{p}<0.05)$.

Conclusion: This study found that allowing children to watch video with VR headset due to dressing change is an effective way to distract attention and decrease pain and fear levels.
\end{abstract}

Keywords: Child, cartoon distraction, dressing change, fear and pain, pediatric nurse randomized controlled trial, virtual reality

\section{Introduction}

Perception of pain is influenced by a combination of various emotional and behavioral factors, including age, gender, social environment, culture, education and experiences $(1,2)$. Dressing changes after the surgery, injection, bloodletting and similar healthcare interventions are the primary sources of fear experienced by hospitalized children. Pain that stems from these procedural interventions are defined as procedural pain $(3,4)$. Parents are mostly concerned with dressing change after abdominal surgery since it causes pain and fear among their children $(3,5)$. Fear and anxiety are considered as two important factors that cause procedural pain due to dressing change. On addition, negative pain experiences during procedural interventions may have life-long effects on children (6). 
Avoiding pain, sorrow and suffering during healthcare delivery is an important professional responsibility of nurses (7). The clinical guideline of American Pain Society (APS) recommends the use of different pharmacological and non-pharmacological modalities for the treatment of postoperative pain in children (8). Similarly, the American Society of Pain Management Nursing (ASPMN) recommends non-pharmacological modalities in order to reduce analgesic medication use and improve the quality of life by eliminating pain. APS also recommends the use of cognitive-behavioral modalities for pain management in children (8).

Distracting is a frequently used technique of pain management $(6,9,10)$. Lee et al. (11) found that watching animated cartoons was a cheap and very effective way to alleviate preoperative anxiety of children aged 3 to 7 years. Lange et al. (12) reported that virtual reality (VR) distraction reduced behavioral pain and anxiety of children who received painful intervention. The systematic review of Luo et al. (13) recommended combining VR distraction and analgesics for procedural pain management.

During invasive interventions, pediatric nurses use distraction techniques in order to reduce pain. These methods have positive effects on not only the children and their parents but also the nurses who provide healthcare. We did not find any studies in the literature that compared the effects of watching videos with a VR headset with watching a cartoon from a tablet computer on pain reduction in children while undergoing dressing change after abdominal surgery. This experimental study aimed to compare the effects of VR and cartoons as a distraction while undergoing dressing change on the pain and fear levels of children between 7 and 10 years of age who had undergone appendectomy or other minor abdominal surgery.

\section{Research Hypotheses}

1. Hypothesis ( $\mathrm{HO})$ : Distracting methods such as watching cartoons or VR do not affect the pain and fear while undergoing a dressing change in children.

2. Hypothesis (H1): Children who use VR glasses (Group B) for pain distraction will have less pain and fear while undergoing a dressing change than children watching cartoons (Group C).

3. Hypothesis ( $\mathrm{H} 1$ ): Children watching cartoons (Group C) will have less pain and fear while undergoing a dressing change than children in the control group (Group A).

\section{Materials and Methods}

This randomized-controlled experimental study was conducted on children aged 7 to 10 years, who visited the pediatric surgery department of a training and research hospital and underwent abdominal surgery between $1^{\text {st }}$ November 2018 and 30 $0^{\text {th }}$ November 2019. The study aimed to compare the effects of VR and cartoon distraction on pain and fear levels while undergoing a dressing change in children who had undergone appendectomy or other minor abdominal surgeries. The sample size was calculated according to the data of a similar study (5) in which we set the $C^{*}$ Power (3.1.0) of the test (1- $\beta$ ) as 0.80 and the significance level $\alpha$ as 0.05 . Each of the three groups required 32 individuals and the study was completed with a total number of 96 participants. The participants were stratified according to age and gender variables and randomized into control and intervention groups. Research randomizer software (https://www.randomizer.org/) was used for the homogenous allocation of the participants. Before entering the data on sample size, sets 1, 2 and 3 were used as titles to indicate the control, VR distraction and cartoon distraction groups. The order of the participants in the sample was randomly determined by the software. The children were allocated to the set 1,2 and 3 groups according to their date of hospitalization (Figure 1).

\section{Inclusion Criteria:}

- At least two days passed since the operation,

- Age ranging from 7-10 years,

- Voluntary participation by parents and child,

- Having undergone appendectomy or other small abdominal surgery,

- Parents and child who speak and understand Turkish.

\section{Exclusion Criteria:}

- Having received pain killers or sedative medication in last 6 hours.

- History of epilepsy, migraine or vestibular disease,

- Physical or mental health problems that prevent communication.

\section{Data Collection Tools}

The personal information form on children and parents (PIFCP), Wong-Baker faces pain rating scale (WBFPS) and the children's fear scale (CFS) were used for data collection. The PIFCP was prepared by the researchers by using the relevant literature. The form included 11 close-ended questions on the sociodemographic characteristics of the children and their parents, the medical history of the children, and the factors that may influence pain and fear levels of the children, including previous surgeries, prior experience of 
dressing changes, the length of hospital stay and chronic diseases.

WBFPS shows six faces and asks children between 3 and 18 years of age to self-assess their level of pain. The first face on the far left indicates "no hurt" and represents a pain score of 0 whereas the sixth face on the far right indicates "hurts worst" and represents a score of 10. The Cronbach's alpha test $(r=86)$ was used for reliability (14). WBFPS was assessed using self-report and reports from the parents, the researcher and the nurse who changed the dressing in this study.

CFS was developed by McMurtry in 2011. The Turkish validity and reliability of the scale was assessed by Gerçeker et al. (15) in 2018. The scale shows five faces and asks the children between 5 and 10 years of age to self-assess their level of fear. The first face on the far left indicates "not

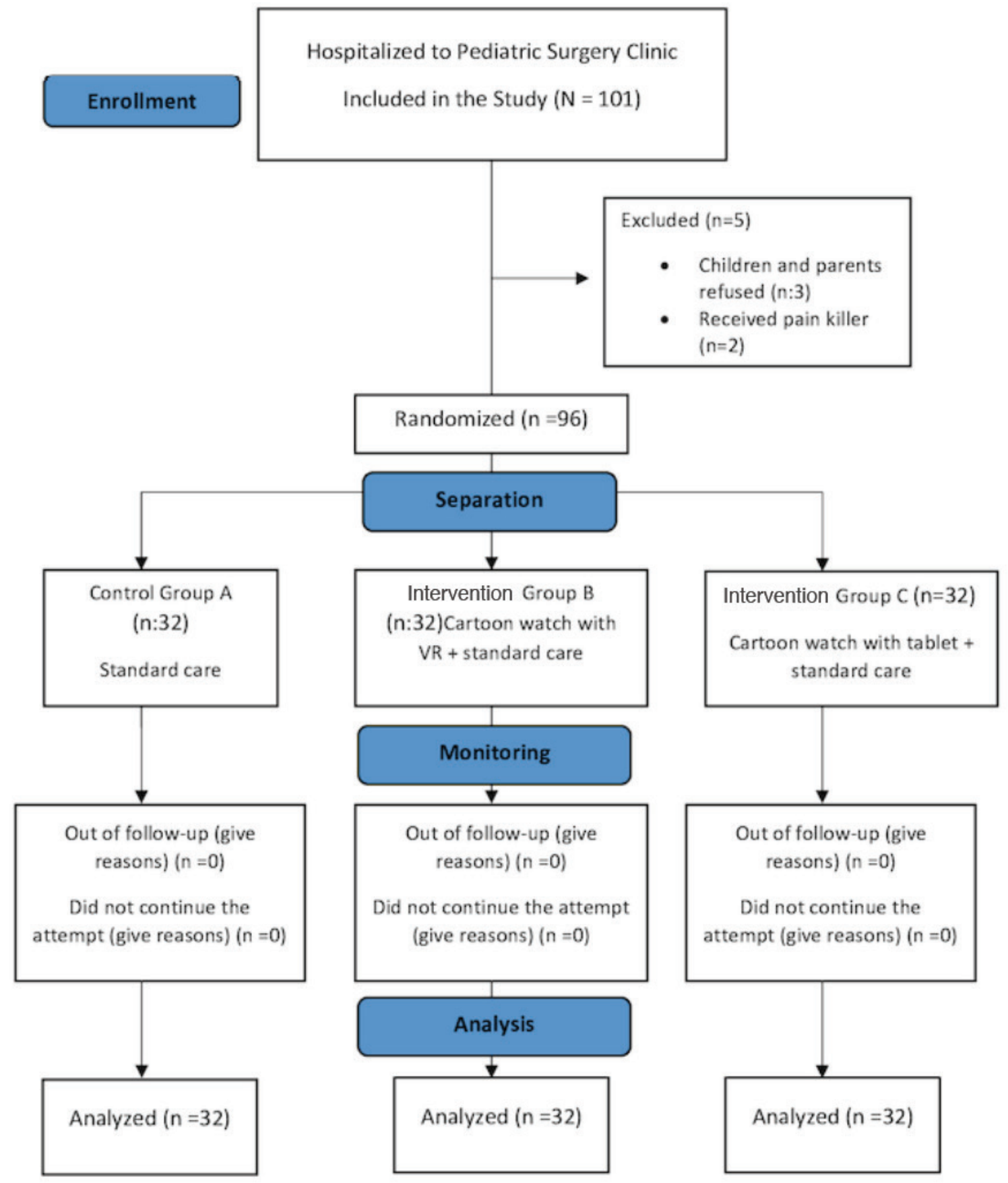

Figure 1. Consort flow diagram 
scared at all" and represents a fear score of 0 whereas the fifth face on the far right indicates "the most scared possible" and represents a fear score of 4 (15).

We used a white 3D PREO myVRbox VR headset. The VR headset transforms a display from a mobile phone, computer or other technological device with LED, LCD or Plasma screens to a more realistic image by creating visual illusion (http://acikarsiv.beun.edu.tr/xmlui/bitstream/ handle/20.500.12628/9401/G\%c3\%b6ksu\%2c\%20Fatma. pdf? sequence=1\&isAllowed=y). The VR headset was supplied by the researcher and disinfected after each use. Additionally, an Apple A1823 iPad tablet was used by the children to watch a cartoon. The tablet was supplied by the researcher and disinfected after each use (Figure 2, 3).

\section{Data Collection Procedures}

Study data was collected over a period of one year $\left(1^{\text {st }}\right.$ November $2018 / 30^{\text {th }}$ November 2019). Before starting the research, we obtained institutional and ethics committee

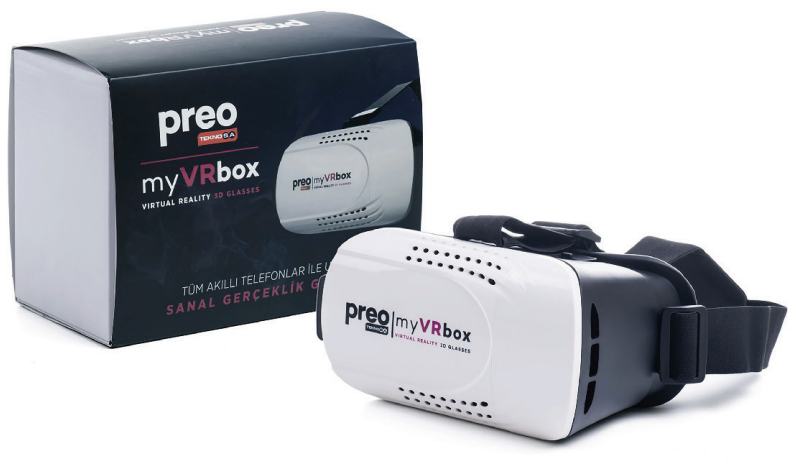

Figure 2. VR glasses used in data collection VR: Virtual reality

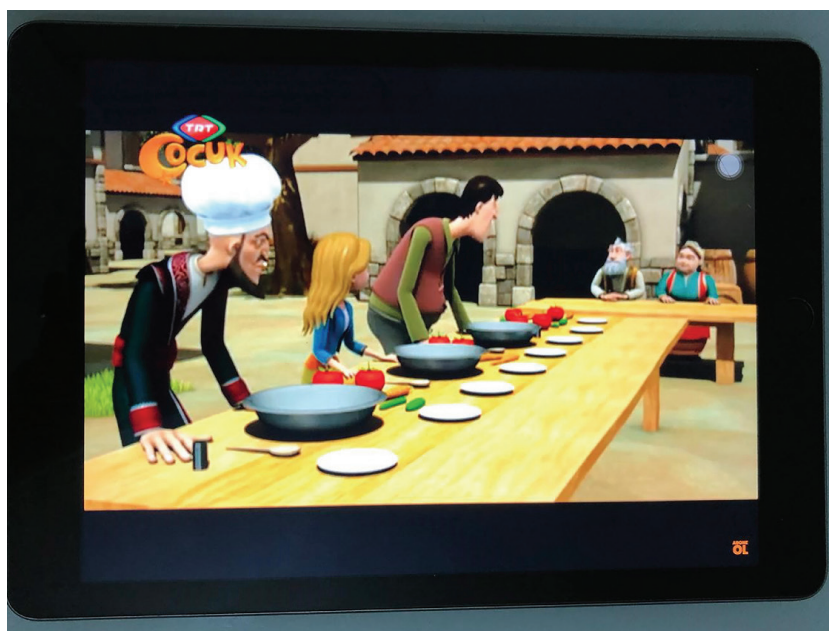

Figure 3. Cartoon showing children on tablet while collecting data permission and permission and permission from the authors to use the scales. We also obtained verbal and written informed consent of the participant children and their parents.

Dressing change in all groups was performed by the same pediatric nurse, who had been working in the department of pediatric surgery for three years. It took place in the dressing room of the pediatric surgery department, where the parents and the researchers were present.

The first phase of the research started with the determination of the samples that matched the inclusion criteria (96 children). Next, the aim and scope of the research were explained to the children and their parents by the researcher. In the second stage, 96 children were allocated to the control and the intervention groups, with 32 participants in each group.

\section{Control Group A ( $n=32)$}

Group A was the control group that received their dressing change without any intervention. The dressing room was located in the clinic. The children were with their parents during the dressing change. Before the dressing, the researcher recorded the demographic characteristics via the Personal Information Form. The children and their parents were informed about WBFPS and CFS and pain and fear levels were evaluated through the expression of the child. The dressing took 8-10 minutes. After the dressing change, pain and fear levels were assessed by the researcher.

\section{Implementation Phase}

Children in Group B watched a video with VR headset while undergoing a dressing change $(n=32)$. Firstly, the researcher prepared the mobile VR support system for use. Secondly, the parent and child were brought to the dressing room. Then, their demographic characteristics were recorded to the PIFCP. Before the evaluation of pain and fear levels, the VR glasses were shown to the children and they were allowed to examine them. After this, the mobile phone was attached to the VR glasses. Then, the VR glasses were placed on the child's eyes and were placed in a comfortable position. The VR headset was switched on three minutes before the dressing change and it was on until the dressing change ended. For group B, 3D-VR VIDEOS 234 SBS VR Video 2k Google cardboard was used. The dressing change was completed in about 8-10 minutes. After the dressing change, pain and fear levels were assessed by the researcher. Finally, the VR glasses and the mobile phone were disinfected. 
Children in Group $C$ watched cartoons on a tablet $(n=32)$. All steps of group B were also applied for group C (e.g: Demographic characteristics were recorded and an assessment for pain and fear was carried out). The "Keloğlan: Food Competition" cartoon was used for Group C. For group C, a different cartoon had to be chosen than for Group B because the cartoon was not adapted to VR glasses. The tablet was given to the children three minutes before the dressing change and they were allowed to lie down in a comfortable position. Then, the tablet was switched on by the researcher and the dressing was changed by the nurse. The process took about 8-10 minutes. After the dressing change, the children were asked to show the faces that reflected their fear and pain levels during the intervention on CFS and WBFPS. The researchers marked the faces shown by the participants.

\section{Statistical Analysis}

The collected data were analyzed using NCSS (Number Cruncher Statistical System) 2007 (Kaysville, Utah, USA) software. Statistical significance for all analysis was set at 0.05. Mean, standard deviation, median, frequency, percentage and minimum-maximum values were used as descriptive analysis. The Wilcoxon sign-rank test was used for the comparison of quantitative data without normal distribution and the Kruskal-Wallis test was performed for inter-group comparison. Dunn's test was used for paired comparison and Bonferroni correction was used for p-values. Spearman's Rho correlation analysis was used to evaluate the relationship between variables. Pearson's chi-square test and Fisher-FreemanHalton exact test were used for the comparison of qualitative data.

\section{Ethical Considerations}

We obtained permission from Acıbadem University and Acıbadem Health Institutions Medical Research Ethics Committee (ATADEK: 2018-11/11, dated: 26.07.2018) and institutional permission from University of Health Sciences Turkey, İstanbul Bağcılar Training and Research Hospital (no: 82998542-771-21701, dated: 16.11.2018). Health professionals working at the department of pediatric surgery of University of Health Sciences Turkey, İstanbul Bağcılar Training and Research Hospital were informed about the research. The children and their parents were informed about the aim and the scope of the research. Verbal and written informed consent of the parents and verbal informed consent of the children were obtained. The participants and their parents were informed that they could withdraw at any time without any reason.

\section{Results}

Participant characteristics: The mean age of the participants was $8.58 \pm 1.13$ years, $56.3 \%(n=54)$ were male whereas the remaining $43.7 \%(n=42)$ were female. It was observed that majority of the children $(n=85)$ had been operated on their right abdomen. Most of the children's $(n=59)$ pain level measurements were evaluated in postop 3-5 days (Table I). There was no statistically significant difference between the three groups in terms of their descriptive characteristics, such as age, gender, surgical history, experience and time of dressing change, dressing site or chronic diseases ( $p>0.05$ ) (Table I).

Pain scores and comparison of the groups: The mean WBFPS scores of the control, VR and cartoon distraction groups while undergoing dressing change were 3.56 \pm 1.74 , $0.44 \pm 0.98$ and $1.63 \pm 1.56$, respectively. The difference between the groups was statistically significant $(p=0.001$; $\mathrm{p}<0.01$ ) (Table II). Paired comparison to reveal the source of the difference showed that the mean WBFPS scores of the cartoon and VR distraction groups were lower than the control group and the mean WBFPS score of the VR distraction group was lower than cartoon distraction group (Table II, III, Figure 4). The $2^{\text {nd }}$ and $3^{\text {rd }}$ Hypotheses were confirmed by these findings.

Fear scores and comparison of the groups: The mean CFS scores for the control, VR and cartoon distraction groups while undergoing dressing change were 2.50 \pm 0.67 , $0.50 \pm 0.92$ and $1.09 \pm 0.93$, respectively. The difference between the groups was statistically significant $(p=0.001$; $p<0.01$ ) (Table III). Paired comparison to reveal the source of the difference showed that the mean CFS scores of the

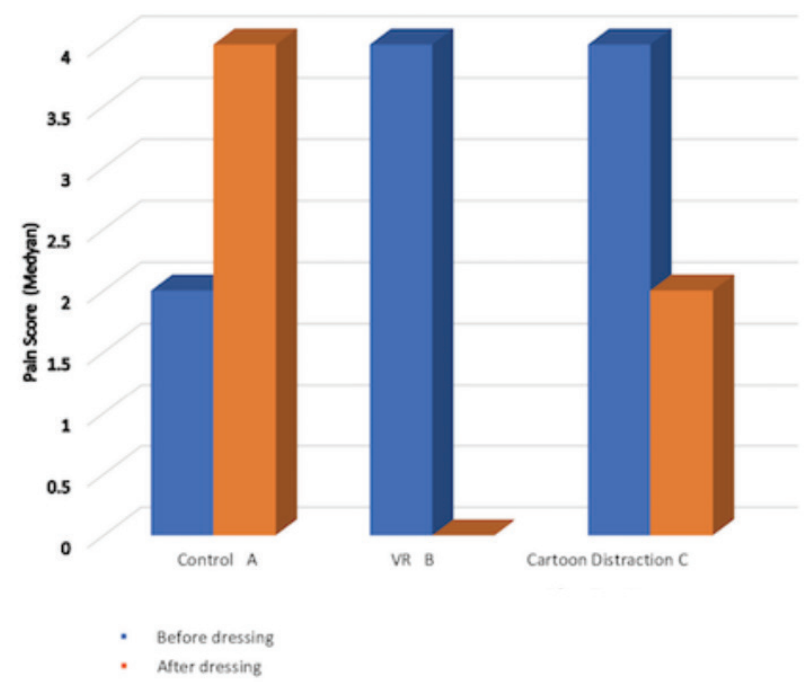

Figure 4. Pain score before and after 
cartoon and VR distraction groups were lower than the control group and the mean CFS score of the VR distraction group was lower than cartoon distraction group. These findings confirmed hypotheses 2 and 3 (Table III).

\section{Discussion}

This study examined the effects of two different distraction methods on the pain and fear levels of children. This study aimed to compare the effects of VR and cartoons as a distraction to pain and fear while undergoing a dressing change of children between 7 and 10 years of age who had undergone abdominal surgery. The VR distraction was more effective than the cartoon distraction for reducing pain and fear while undergoing a dressing change.

Existing studies show that children suffer from pain and fear due to procedures. Procedural pain may have adverse effects on children and may increase in later interventions if it is not prevented or properly managed $(16,17)$. This, in turn, may result in an unwillingness to receive procedures and even a delay in treatment $(3,18)$. For this reason, all health professionals agree on the point that effective methods should be used to reduce pain and fear

\section{Table I. Characteristics of children $(n=96)$}

\begin{tabular}{|c|c|c|c|c|c|c|c|}
\hline & \multicolumn{2}{|c|}{$\begin{array}{l}\text { Control group A } \\
(n=32)\end{array}$} & \multicolumn{2}{|c|}{ VR group $B(n=32)$} & \multicolumn{2}{|c|}{$\begin{array}{l}\text { Cartoon distraction group C } \\
(n=32)\end{array}$} & Analysis \\
\hline \multicolumn{8}{|c|}{ Characteristics of children } \\
\hline & $\mathbf{n}$ & $\%$ & $\mathbf{n}$ & $\%$ & $\mathbf{n}$ & $\%$ & \\
\hline \multicolumn{8}{|l|}{ Age } \\
\hline 7 years 11 months & 5 & 15.7 & 10 & 31.2 & 7 & 21.9 & \multirow{4}{*}{$p=0.711$} \\
\hline 8 years 11 months & 10 & 31.2 & 7 & 21.9 & 6 & 18.8 & \\
\hline 9 years 11 months & 8 & 25.0 & 8 & 25.0 & 8 & 25.0 & \\
\hline 10 years & 9 & 28.1 & 7 & 21.9 & 11 & 34.3 & \\
\hline \multicolumn{8}{|l|}{ Gender } \\
\hline Female & 13 & 40.6 & 16 & 50.0 & 13 & 40.6 & \multirow{2}{*}{$p=0.683$} \\
\hline Male & 19 & 59.4 & 16 & 50.0 & 19 & 59.4 & \\
\hline \multicolumn{8}{|l|}{ Surgery history } \\
\hline No & 25 & 78.1 & 26 & 81.3 & 27 & 84.4 & \multirow{2}{*}{$p=0.815$} \\
\hline Yes & 7 & 21.9 & 6 & 18.7 & 5 & 15.6 & \\
\hline \multicolumn{8}{|c|}{ Dressing change history } \\
\hline No & 31 & 97 & 29 & 90.6 & 30 & 93.8 & \multirow{2}{*}{$p=0.869$} \\
\hline Yes & 1 & 3.1 & 3 & 9.4 & 2 & 6.2 & \\
\hline \multicolumn{8}{|c|}{ Dressing change day } \\
\hline 0-2. day & 2 & 6.2 & 0 & 0.0 & 2 & 6.2 & \multirow{5}{*}{$p=0.630$} \\
\hline 3-5. day & 22 & 68.8 & 18 & 56.3 & 19 & 59.4 & \\
\hline 6-8. day & 6 & 18.8 & 11 & 34.3 & 7 & 21.9 & \\
\hline 9-11. day & 2 & 6.2 & 3 & 9.4 & 3 & 9.4 & \\
\hline 12-14. day & 0 & 0.0 & 0 & 0.0 & 1 & 3.1 & \\
\hline \multicolumn{8}{|l|}{ Dressing place } \\
\hline Right abdomen & 28 & 87.5 & 27 & 84.4 & 30 & 93.8 & \multirow{2}{*}{$p=0.611$} \\
\hline Left abdomen & 4 & 12.5 & 5 & 15.6 & 2 & 6.2 & \\
\hline \multicolumn{8}{|l|}{ Chronic illness } \\
\hline No & 31 & 96.9 & 29 & 90.6 & 30 & 93.8 & \multirow{2}{*}{$p=0.869$} \\
\hline Yes & 1 & 3.1 & 3 & 9.4 & 2 & 6.2 & \\
\hline
\end{tabular}


due to procedures. The ASPMN states that nurses should intervene in order to provide the best pain management before, during and after procedures based on the needs of the patients, the setting and the situation (18). Within this context, distraction is a widely used technique of pain management in pediatric clinics. Various techniques independently employed by nurses have decreased the pain and fear of children $(3,19)$.

Pediatric nurses, who have been with pediatric patients for longer than other team members, can apply nonpharmacological methods to reduce pain and fear more correctly and independently. Distraction methods that can be applied to age groups of children by nurses are VR glasses, video/television streaming, playing computer game, cold/ hot applications, giving toys and breathing exercises (20). VR is a relatively new technique to provide distraction and it might be more effective than other traditional methods (21).

In the systematic review and meta-analysis study conducted by Eijlers et al. (21), it was reported that the VR method reduces pain and anxiety in children. It was also reported that "the VR interventions for pain and anxiety were potentially more efficacious for younger than for older children" (21).
Pain and fear scores of the children in this study, who watched a video with a VR headset were lower than those children who watched a cartoon from a tablet or did not watch anything, and the difference between the groups was statistically significant $(p<0.01)$ (Table II). Mott et al. (22) found that augmented VR systems alleviated the pain levels of children undergoing a burns dressing change between the ages of 3.5 and 14 years. Das et al. (23) analyzed the effects of playing a VR game on procedural pain of children with acute burn injuries between the ages of 5 and 18 years and found that those children who received pharmacological analgesia had higher pain scores than the children who received pharmacological analgesia with a VR game. The randomized-controlled trial of Hua et al. (10) on the effects of VR distraction on pain relief while undergoing a dressing change in children aged from 4 to 16 years with chronic wounds found that VR distraction lowered pain and fear scores and reduced the length of time needed for the dressing change. The pilot study of Gershon et al. (24) found that VR distraction reduced pain and anxiety in children with cancer, aged from 7 to 19 years, whose treatment protocols required access to subcutaneous venous port device. Khadra et al. (25) conducted a pilot study to evaluate the impact of VR distraction on procedural pain management in children

Table II. Comparison of pain score pre-dressing and post-dressing

\begin{tabular}{|c|c|c|c|c|c|}
\hline & & \multicolumn{4}{|l|}{ Groups } \\
\hline & & Control group A & VR group $B$ & Cartoon distraction group C & p-value \\
\hline Pre-dressing & $\begin{array}{l}\text { Min-max (median) } \\
\text { Mean+SD }\end{array}$ & $\begin{array}{l}0-8(2) \\
1.8 \pm 1.83\end{array}$ & $\begin{array}{l}2-6(4) \\
3.44 \pm 1.37\end{array}$ & $\begin{array}{l}0-10(4) \\
3.37 \pm 1.86\end{array}$ & $\begin{array}{l}x^{2}: 19,325 \\
{ }^{\mathbf{0}} .001^{* *}\end{array}$ \\
\hline \multirow[t]{2}{*}{ Post-dressing } & $\begin{array}{l}\text { Min-max (median) } \\
\text { Mean+SD }\end{array}$ & $\begin{array}{l}0-8(4) \\
3.56 \pm 1.74\end{array}$ & $\begin{array}{l}0-4(0) \\
0.44 \pm 0.98\end{array}$ & $\begin{array}{l}0-6(2) \\
1.63 \pm 1.56\end{array}$ & $\begin{array}{l}x^{2}: 46,139 \\
\mathbf{c o . 0 0 1 * *}^{*}\end{array}$ \\
\hline & $\begin{array}{l}\text { Difference } \\
\mathbf{p}\end{array}$ & $\begin{array}{l}1.69 \pm 1.45 \\
\text { d0.001** }\end{array}$ & $\begin{array}{l}-3.00 \pm 1.14 \\
\text { do.001** }\end{array}$ & $\begin{array}{l}1.75 \pm 1.59 \\
\text { d0.001** }\end{array}$ & $\begin{array}{l}x^{2}: 62,933 \\
\text { c0.001** }\end{array}$ \\
\hline
\end{tabular}

Table III. Comparison of pain score pre-dressing and post-dressing

\begin{tabular}{|c|c|c|c|c|c|}
\hline & & \multicolumn{3}{|l|}{ Groups } & \multirow{2}{*}{$\begin{array}{l}\text { Test value } \\
\text { p-value }\end{array}$} \\
\hline & & Control group A & VR group $B$ & Cartoon distraction group $\mathrm{C}$ & \\
\hline Pre-dressing & $\begin{array}{l}\text { Min-max (median) } \\
\text { Mean+SD }\end{array}$ & $\begin{array}{l}0-3(2) \\
1.75 \pm 0.88\end{array}$ & $\begin{array}{l}0-4(2) \\
2.47 \pm 1.05\end{array}$ & $\begin{array}{l}0-4(2) \\
1.91 \pm 0.99\end{array}$ & $\begin{array}{l}x^{2}: 8,658 \\
\mathbf{c o d o 1}^{* *}\end{array}$ \\
\hline \multirow[t]{2}{*}{ Post-dressing } & $\begin{array}{l}\text { Min-max (median) } \\
\text { Mean+SD }\end{array}$ & $\begin{array}{l}1-4(3) \\
2.50 \pm 0.67\end{array}$ & $\begin{array}{l}0-4(0) \\
0.50 \pm 0.92\end{array}$ & $\begin{array}{l}0-3(1) \\
1.09 \pm 0.93\end{array}$ & $\begin{array}{l}x^{2}: 49,234 \\
\mathbf{c o s}^{*} \mathbf{0 0 1 *}\end{array}$ \\
\hline & $\begin{array}{l}\text { Difference } \\
\mathbf{p}\end{array}$ & $\begin{array}{l}0.75 \pm 0.67 \\
\text { do.001** }\end{array}$ & $\begin{array}{l}-1.97 \pm 1.18 \\
\text { do.001** }\end{array}$ & $\begin{array}{l}-0.81 \pm 1.15 \\
\text { do.001** }\end{array}$ & $\begin{array}{l}x^{2}: 56,372 \\
{ }^{\prime} 0.001^{* *}\end{array}$ \\
\hline
\end{tabular}


aged from 2 months to 10 years with burn injuries requiring a hydrotherapy session and found that projector-based VR was a feasible and acceptable intervention for the management of procedural pain. Asl Aminabadi et al. (26) studied the impact of VR distraction on pain and anxiety levels during dental treatment in 120 children aged from 4 to 6 years and found that VR eyeglasses decreased pain perception and state anxiety. In this sense, our findings are in line with the literature. Therefore, we may conclude that the VR headset is an effective method to distract the attention of children and reduce their pain and anxiety while undergoing a dressing change.

The findings of various studies support the preposition that cartoon distraction is an effective and practical method to reduce pain due to medical procedures $(3,27,28)$. In our study, the cartoon distraction group obtained lower pain and fear scores than the control group and the difference between the groups was statistically significant $(p<0.01)$ (Table II and III). Similar to our findings, Cohen et al. (27) found that watching a cartoon during immunizations was an effective and practical intervention to reduce the pain and anxiety of 92 children between the ages of 4 and 6 years. Downey and Zun (28) conducted a study on 100 children between 3 and 18 years of age who visited an emergency department due to acute pain from any cause. They found that starting to watch a cartoon five minutes before a painful intervention was an effective method to reduce perceived pain (28). The quasi-experimental study of James et al. (29) on 50 children between 3 and 6 years of age found that an animated cartoon was an effective distraction strategy to reduce pain. Devi et al. (30) reported that perceived pain decreased after the intervention of an animated cartoon video as a distraction strategy among preschoolers. Lobo and Umarani (31) conducted a quasiexperimental study on 60 children of 3-6 years of age and found that cartoon distraction reduced venipuncture pain. Similarly, Yoo et al. (32) found that animation distraction using a laptop computer reduced perceived pain during venipuncture in 40 children between 3 and 7 years of age. Kuo et al. (33) allocated 276 children aged 3 to 7 years into control, picture book and animated cartoon groups and found that cartoon distraction was a more effective method to reduce behavioral stress for children aged 4 to 5 years. Wang et al. (34) randomized 300 children aged 8 to 9 years into cartoon distraction, psychological intervention and control groups and found that the pain score of the cartoon distraction group was lower than the psychological intervention group.
Lee et al. (11) compared the effects of viewing an animated cartoon with playing with a favorite toy on preoperative anxiety in 130 children between 3 and 7 years of age and found that allowing children to watch animated cartoons was a very effective method to alleviate preoperative anxiety. Gupta et al. (35) randomized 70 children of 7 years of age into the groups of children who were held by a family member during venipuncture and child who were held by family member in conjunction with an animation distraction during venipuncture and they found that children who received an animation distraction intervention had lower levels of pain. Hussein (36) allocated 75 school age children into control, active distraction (i.e. playing a video game) and passive distraction (i.e. watching a cartoon) groups and they found that the pain scores of the active distraction group was lower than the other groups. The findings of Hussein (36) contradicts our findings. This difference may be related with the active interaction of the children with the video game in the study of Hussein (36), which may be a better distraction technique than a passive cartoon distraction. Similarly, Inan and Inal (37) randomized 180 children of 6 to 10 years of age into control, video game, cartoon and parent distraction groups and found that playing video games was the most effective method to reduce pain perception in children during venipuncture. The findings of Inan and Inal (37) are also different from our findings and this difference may be related with the possibility that video game as an active distraction technique may be more effective than a passive cartoon distraction technique.

In this study, children who watched a video with a VR headset were the active distraction group whereas those children who watched a cartoon on a tablet were the passive distraction group. The literature suggests that both distraction techniques are effective to reduce pain and fear among children during dressing change. The VR distraction group obtained significantly lower pain and anxiety scores than the cartoon distraction and the control groups (21). This finding is in line with the literature, which suggests that active distraction methods are more effective than passive distraction methods as a means of reducing anxiety and pain. However, no studies in the literature had compared the effectiveness of VR and cartoon distraction. This study's findings imply that VR glasses allow children to actively interact with the video so that it was more effective than the passive cartoon distraction technique as a means of reducing fear and pain. 
Although there are many studies that use VR technology to reduce pain and anxiety in pediatric patients (21), in clinics, it is not widely practiced by nurses or other healthcare professionals. For the widespread uses of the VR method in the clinic, it may be necessary to use more interactive VR glasses where children can also participate instead of only watching. It is also believed that standards should be established for evidence to be used in clinics.

\section{Study Limitations}

The sample of this study is limited to those patients from the department of pediatric surgery in University of Health Sciences Turkey, İstanbul Bağcılar Training and Research Hospital. For this reason, the research findings may only be generalized to the patients who have similar characteristics to our sample.

\section{Conclusion}

This randomized-controlled study, which aimed to assess the effects of VR and cartoon distraction techniques on pain and anxiety in children while undergoing a dressing change, found that the VR distraction method was more effective than the cartoon distraction method as a means of reducing fear and pain in children aged 7 to 10 years of age who had undergone abdominal surgery.

Within this context;

- Using a VR headset and allowing children to watch a cartoon should be extended as distraction techniques to reduce pain and fear of children while undergoing a dressing change.

- Procedural pain management guidelines prepared for the pediatric patients should include VR and cartoon distraction techniques.

Acknowledgements: The authors would like to thank nurse Burçin Güngör who made the dressing change and all of the participants of this study.

\section{Ethics}

Ethics Committee Approval: We obtained permission from Acıbadem University and Acıbadem Health Institutions Medical Research Ethics Committee (ATADEK: 2018-11/11, dated: 26.07.2018).

Informed Consent: Verbal and written informed consent of the parents and verbal informed consent of the children were obtained.

Peer-review: Externally peer-reviewed.

\section{Authorship Contributions}

Concept: F.Ö., B.U., Design: F.Ö., B.U., Data Collection or Processing: F.Ö., B.U., Analysis or Interpretation: F.Ö., B.U., Writing: F.Ö., B.U.

Conflict of Interest: The authors declared no conflict of interest.

Financial Disclosure: The authors declared that this study received no financial support.

\section{References}

1. Aygin D, Var G. Pain Management In Trauma Patients And Nursing Approaches. Sakarya Medical Journal 2012; 2:61-70.

2. Aktaş H, Ünal E, Gülhan NF. Approach to Pain in Burn Patients. Hacettepe University Faculty Of Health Sciences Journal 2016; 3:46-57.

3. Inal S, Canbulat N. Using of Distraction Methods on Procedural Pain Management of Pediatric Patients. I Curr Pediatr 2015; 2:372-8.

4. World Union of Wound Healing Societies. Principles of best practice: Minimising pain at wound dressing-related procedures. A consensus document. London, MEP Ltd, 2004.

5. Canbulat N, İnal S, Sönmezer H. Efficacy of distraction methods on procedural pain and anxiety by applying distraction cards and kaleidoscope in children. Asian Nurs Res (Korean Sc Nurs Sci) 2014; 8:23-8.

6. He HG, Jahja R, Sinnappan R, et al. Singaporean nurses' provision of guidance to parents on non-pharmacological postoperative pain-relief methods: An educational intervention study. Nurs Health Sci 2011; 13:344-51.

7. Freitas DMO, Spadoni VS. Is virtual reality useful for pain management in patients who undergo medical procedures? Einstein (São Paulo) 2019; 17:4837.

8. Chou R, Gordon DB, de Leon-Casasola OA, et al. Management of Postoperative Pain: A Clinical Practice Guideline From the American Pain Society, the American Society of Regional Anesthesia and Pain Medicine, and the American Society of Anesthesiologists' Committee on Regional Anesthesia, Executive Committee, and Administrative Council. / Pain 2016; 17:131-57.

9. Özveren $\mathrm{H}, \mathrm{Uçar} H$. The Knowledge of Student Nurses on Some Non-Pharmacological Methods Used in the Pain Control. Hacettepe University Faculty of Health Sciences Nursing Journal 2009; 16:59-72.

10. Hua Y, Qiu R, Yao WY, Zhang Q, Chen XL. The effect of virtual reality distraction on pain relief during dressing changes in children with chronic wounds on lower limbs. Pain Manag Nurs 2015; 16:685-91.

11. Lee J, Lee J, Lim H, et al. Cartoon distraction alleviates anxiety in children during induction of anesthesia. Anesth Analg 2012; 115:1168-73.

12. Lange $B$, Williams $M$, Fulton I. Virtual reality distraction during pediatric medical procedures. Pediatric Pain Letter 2006; 8:6-10.

13. Luo H, Cao C, Zhong J, Chen J, Cen Y. Adjunctive virtual reality for procedural pain management of burn patients during dressing change or physical therapy: A systematic review and meta- 
analysis of randomized controlled trials. Wound Repair Regen 2019; 27:90-101.

14. Savino F, Vagliano L, Ceratto S, Viviani F, Miniero R, Ricceri F. Pain assessment in children undergoing venipuncture: The WongBaker faces scale versus skin conductance fluctuations. Peer ) 2013; 1:37.

15. Gerçeker GÖ, Ayar D, Özdemir Z, Bektaş M. Gaining of Children's State Anxiety and Children's Fear Scale to Turkish Language. E-Journal of Dokuz Eylül University Nursing Faculty. 2018; 11:9-13.

16. Ducharme J. Acute pain and pain control: State of the art. Ann Emerg Med 2000; 35:592-603.

17. Weisman SJ, Bernstein B, Schechter NL. Consequences of inadequate analgesia during painful procedures in children. Arch Pediatr Adolesc Med 1998; 152:147-9.

18. Czarnecki ML, Turner HN, Collins PM, Doellman D, Wrona S, Reynolds J. Procedural pain management: A position statement with clinical practice recommendations. Pain Manag Nurs 2011; 12:95-111.

19. Cura Üzen \$̧, Oğul T, Kurt FY. Complementary and alternative medicine practices used for relieving pain in pediatric age groups. Zeynep Kamil Med I 2018; 49:126-9.

20. Kara R, Bal Yılmaz H. Examining the Methods Used to Reduce the Interventional Pain by Nurses in Pediatric Clinics. Journal of Education and Research in Nursing 2020; 17:104-11. DOI: 10.5222/HEAD.2020.13334

21. Eijlers R, Utens EMWJ, Staals LM, et al. Systematic Review and Meta-analysis of Virtual Reality in Pediatrics: Effects on Pain and Anxiety. Anesth Analg 2019; 129:1344-53.

22. Mott I, Bucolo S, Cuttle L, et al. The efficacy of an augmented virtual reality system to alleviate pain in children undergoing burns dressing changes: A randomised controlled trial. Burns 2008; 34:803-8.

23. Das DA, Grimmer KA, Sparnon AL, McRae SE, Thomas BH. The efficacy of playing a virtual reality game in modulating pain for children with acute burn injuries: A randomized controlled trial [ISRCTN87413556]. BMC Pediatr 2005; 5:1.

24. Gershon J, Zimand E, Pickering M, Rothbaum BO, Hodges L. A pilot and feasibility study of virtual reality as a distraction for children with cancer. I Am Acad Child Adolesc Psychiatry 2004; 43:1243-9.

25. Khadra C, Ballard A, Déry J, et al. Projector-based virtual reality dome environment for procedural pain and anxiety in young children with burn injuries: A pilot study. I Pain Res 2018; 14:34353.
26. Asl Aminabadi N, Erfanparast L, Sohrabi A, Ghertasi Oskouei $S$, Naghili $A$. The impact of virtual reality distraction on pain and anxiety during dental treatment in 4-6 year-old children: A randomized controlled clinical trial. I Dent Res Dent Clin Dent Prospects 2012; 6:117-24.

27. Cohen LL, Blount RL, Panopoulos G. Nurse coaching and cartoon distraction: An efective and practical intervention to reduce child, parent, and nurse distress during immunizations. J Pediatr Psychol 1997; 22:355-70

28. Downey LV, Zun LS. The impact of watching cartoons for distraction during painful procedures in the emergency department. Pediatr Emerg Care 2012; 28:1033-5.

29. James J, Ghai S, Rao K, Sharma N. Effectiveness of "Animated Cartoons" as a distraction strategy on behavioural response to pain perception among children undergoing venipuncture. Nursing and Midwifery Research Journal 2012; 8:198-207.

30. Devi P, Shinde J, Patil NB. Effectiveness of animated cartoon video as a distraction strategy on pain perception during and after venipuncture among preschoolers. International Journal of Psychiatric Nursing 2017; 3:26-31.

31. Lobo MR, Umarani J. Cartoon distraction reduces venipuncture pain among preschoolers-a quasi experimental study. International Journal of Scientific Research 2013; 2:454-6.

32. Yoo H, Kim S, Hur HK, Kim HS. The effects of an animation distraction intervention on pain response of preschool children during venipuncture. Appl Nurs Res 2011; 24:94-100.

33. Kuo HC, Pan HH, Creedy DK, Tsao Y. Distraction-based interventions for children undergoing venipuncture procedures: A randomized controlled study. Clin Nurs Res 2018; 27:467-82.

34. Wang ZX, Sun LH, Chen AP. The efficacy of non-pharmacological methods of pain management in school-age children receiving venepuncture in a paediatric department: A randomized controlled trial of audiovisual distraction and routine psychological intervention. Swiss Med Wkly 2008; 138:579-84.

35. Gupta HV, Gupta VV, Kaur A, et al. Comparison between the analgesic effect of two techniques on the level of pain perception during venipuncture in children up to 7 years of age: A quasi-experimental study. I Clin Diagn Res 2014; 8:1-4.

36. Hussein HA. Effect of active and passive distraction on decreasing pain associated with painful medical procedures among school aged children. World Journal of Nursing Sciences 2015; 1:13-23.

37. Inan $G$, Inal $S$. The impact of 3 different distraction techniques on the pain and anxiety levels of children during venipuncture. Clin J Pain 2019; 35:140-7. 